\title{
OPTIMIZATION OF CONJUGATED LINOLEIC ACID PRODUCTION FROM SAFFLOWER OIL AND PURIFICATION BY LOW TEMPERATURE CRYSTALLIZATION
}

\author{
H. ERINÇ* and I. H. ISLER \\ Department of Food Engineering, Faculty of Engineering, Niğde Ömer Halisdemir University, 51240. Turkey
}

(Received: 24 December 2017; accepted: 18 June 2018)

\begin{abstract}
The first objective of this study was to reveal the effect of temperature and time on the production of CLA isomers from safflower oil. For this purpose, CLA production was conducted at different temperatures $\left(80-240^{\circ} \mathrm{C}\right)$ and over different time durations $(1-10 \mathrm{~h})$. Alkali isomerisation gave a total conversion of $87.8 \%$ under the optimal conditions of $240{ }^{\circ} \mathrm{C}$ and $8 \mathrm{~h}$ (for maximum beneficial isomers), and produced $41.0 \%$ trans- 10 , cis- $12,40.4 \%$ cis- 9 , trans- 11 , and $6.4 \%$ undesirable CLA isomers. The second aim of this study was to determine the effect of temperature and solvents on the purification of CLA isomers. To achieve this, CLA solutions containing different solvents (acetone, methanol, and petroleum ether) were crystallized at several temperatures $\left(0\right.$ to $\left.-85^{\circ} \mathrm{C}\right)$. It was determined that although the highest CLA purities $(94 \%)$ were obtained at $-55^{\circ} \mathrm{C}$ using acetone as the solvent with a yield of $38.1 \%$, the highest yield $\left(89.6 \%\right.$ ) was determined using petroleum ether at $-85{ }^{\circ} \mathrm{C}$ with a purity of $88.1 \%$. This paper presents methods to utilize safflower oil and low temperature crystallization process to inexpensively obtain beneficial CLA.
\end{abstract}

Keywords: conjugated linoleic acid, production, alkali isomerisation, fractional crystallization, purification

The ability of certain foods to help prevent disease and the scientific presentation of their effectiveness in treatment have increased the importance of nutritional support in medicine. In recent years, investigation of the beneficial effects of conjugated linoleic acids (CLAs) on human health has attracted great interest of researchers. In particular, the findings that confirm the role of CLAs in reducing body fat and fortifying the immune system, as well as exhibiting anticarcinogenic effects are considered to be very important (VAN NiEUWENHOVE et al., 2012). CLAs are a group of positional and geometric isomers of linoleic acid (LA). Some CLA isomers, which are natural and functional components, are predominantly present in meat and milk of ruminants and their products. CLAs were first identified by PARIZA and co-workers (HA et al., 1987) as a component of an extract from grilled beef having anticarcinogenic activity. Since then, interest in CLAs has gradually increased as more of their significant effects were discovered, such as the reduction of cancer incidence, decrease in body fat content, and strengthening of the immune system (FerNiE, 2003; Viladomiua et al., 2016). Today, the United States Food and Drug Administration categorizes CLAs as GRAS for some food categories (milk, yogurt, fruit juice, and soy milk). It has also been reported that trans-10, cis-12 CLA show activities that increase energy consumption (RAHMAN et al., 2001), decrease body fat content (GNADIG et al., 2001), and prevent the development of hypertension (NAGAO et al., 2003), and cis-9, trans-11 CLA have anticarcinogenic effect (GNADIG et al., 2001).

\footnotetext{
* To whom correspondence should be addressed.

Phone: +903882254005; fax: +903882250112; e-mail: herinc@ohu.edu.tr
} 
In general, CLAs are chemically produced from LA by alkali isomerisation. This commercial synthesis focuses on maximizing total CLA content without considering the CLA isomers formed. However, not all CLA isomers are beneficial for health, and only some have natural and functional components (VAN NIEUwENHOVE et al., 2012). For this reason, it is necessary to produce and purify useful CLA isomers. MA and co-workers (1999) reported that $160-180^{\circ} \mathrm{C}$ reduced the amount of undesirable CLA isomers during production in case of safflower oil. However, YANG and LiU (2004) reported that $150{ }^{\circ} \mathrm{C}$ and $140 \mathrm{~min}$ were the optimal conditions in the isomerisation for beneficial isomers.

Several studies have been conducted on the purification of CLA concentrates; however, all used the urea crystallization method (KIM et al., 2003; GolI et al., 2008). An alternative method is low temperature crystallization (fractional crystallization) of the oil that is used in the production of fatty acids in the food industry. This process involves the removal of high melting point compounds by cooling. The melting temperatures of free fatty acids differ depending on their structural properties (Gunstone et al., 2007). Therefore, at low temperatures, fatty acids with a high melting point (e.g., saturated fatty acids) crystallize, whereas those with a low melting point (e.g., polyunsaturated fatty acids) remain in the liquid phase (WANASUNDARA et al., 2005). Among the several types of fractional crystallization, solvent fractional crystallization is the most commonly employed. The use of solvents encourages the formation of crystals and increases their yield and purity (CunHA et al., 2009).

The aim of this study was to reveal the effects of temperature and time on the production of beneficial CLA isomers from a high LA content inexpensive oil, safflower oil, and to determine the role of temperature and solvents in the purification of CLA.

\section{Materials and methods}

\subsection{Materials}

Safflower oil was purchased from the local market. CLA standards (trans-9, trans 11-, cis-9, trans-11- and trans-10, cis-12 octadecadienoic acid) were obtained from Sigma-Aldrich Chem. Co. (St. Louis, MO, USA). A mix of 37 fatty acid methyl esters (C4-C24) was purchased from Supelco (Bellefonte, PA, USA). All solvents and chemicals were of chromatographic grade.

\subsection{Hydrolysis of safflower oil}

For this purpose, $500 \mathrm{~g}$ of safflower oil was mixed with $115 \mathrm{~g}$ of potassium hydroxide, 400 $\mathrm{ml}$ of ethanol, and $125 \mathrm{ml}$ of purified water, and saponified in a heater (MS-E104, TOPS Co. Ltd.) for $1 \mathrm{~h}$ under reflux. Then, 0.51 of ice was added for cooling, and $600 \mathrm{ml} \mathrm{of} \mathrm{H}_{2} \mathrm{SO}_{4}$ (4 M) was added to reduce the $\mathrm{pH}$ to 2.2. After phase separation in the separation funnel, extraction was carried out using ether $(2 \times 100 \mathrm{ml})$. The ether was removed by a rotary evaporator (Heidolph Hei-vap, Germany), and the ether residue was further evaporated under vacuum at $50{ }^{\circ} \mathrm{C}$ for $5 \mathrm{~h}$.

\subsection{Purification of LA by low temperature crystallization}

At this stage, the method described by ERINÇ and co-workers (2017) was used. For this purpose, the hydrolyzed fatty acids were dissolved in acetone $\left(50 \mathrm{~g} \mathrm{l}^{-1}\right)$ and mixed very 
slowly ( $48 \mathrm{~h}$ ) in a deep freezer at $-70{ }^{\circ} \mathrm{C}$ for crystallization of fatty acids. The solidified fatty acids were removed by filtration.

\subsection{Fatty acid composition analysis of safflower oil and purified LA}

Fatty acid composition of safflower oil and purified LA were determined by Shimadzu GC2010 equipped with a DB-23 capillary column $(60 \mathrm{~m} \times 0.25 \mathrm{~mm}$ i.d. and $0.25 \mu \mathrm{m}$ film thickness) and a flame ionization detector. Helium $\left(1 \mathrm{ml} \mathrm{min}^{-1}\right)$ was used as carrier gas. The split ratio was 1:80. The working temperatures of the injector, column, and detector were 230,185 , and $240^{\circ} \mathrm{C}$, respectively.

\subsection{CLA production}

The method described by YANG and LiU (2004) was modified and used in CLA production. For this purpose, $10 \mathrm{~g}$ of LA (obtained from safflower oil) was mixed with $5.2 \mathrm{~g}$ of $\mathrm{KOH}$ (40 $\mathrm{ml}$ of ethylene glycol), isomerised using a jacketed heater at different temperatures $\left(80-240{ }^{\circ} \mathrm{C}\right)$ and refluxed for different times $(1-10 \mathrm{~h})$; then, $20 \mathrm{ml}$ of ethanol was added, and the $\mathrm{pH}$ was reduced to 2 by the addition of $6.5 \mathrm{ml}$ of $6 \mathrm{~N} \mathrm{HCl}$. The resulting product was rinsed with pure water $(40 \mathrm{ml})$, then with hexane $(40 \mathrm{ml})$, and finally with $30 \%$ methanol $(40 \mathrm{ml})$, and the solvent was evaporated using a rotary evaporator (Heidolph Hei-vap, Germany) to obtain the CLA solution.

\subsection{Obtaining fatty acid methyl esters by transesterification}

The transesterification method of fatty acids reported by CHRISTIE (1989) was modified to form methyl esters of free fatty acids. For this purpose, $125 \mu \mathrm{lof} \mathrm{H}_{2} \mathrm{SO}_{4}(1 \% \mathrm{w} / \mathrm{v}$ in methanol) was added to $2 \mathrm{mg}$ oil sample and allowed to stand at $70{ }^{\circ} \mathrm{C}$ for $2 \mathrm{~h}$. Then, $150 \mu \mathrm{lof} \mathrm{NaCl}$ solution $(5 \% \mathrm{w} / \mathrm{v})$ was added, it was incubated at $70{ }^{\circ} \mathrm{C}$ for $10 \mathrm{~min}$, and then extracted twice with $15 \mathrm{ml}$ of hexane in a separation funnel. Finally, fatty acid methyl esters were obtained with the addition of $125 \mu \mathrm{l}$ potassium bicarbonate $(4 \% \mathrm{w} / \mathrm{v})$.

\subsection{Purification of CLA by low temperature crystallization}

In this stage, after CLA production under optimum conditions, the resulting product was dissolved in acetone, petroleum ether, and methanol $(5 \mathrm{~g} / 100 \mathrm{ml})$, and mixed very slowly $(48 \mathrm{~h})$ at different temperatures $\left(0\right.$ to $\left.-85^{\circ} \mathrm{C}\right)$ in a deep freezer for crystallization. Solid fatty acids were filtered through a Buchner funnel at crystallization temperatures in a deep freezer and stored at their assigned temperature. The fatty acids were recovered from the filtrate by evaporating the solvent on a rotary evaporator, and then placed in a vacuum oven and maintained at $50{ }^{\circ} \mathrm{C}$ for $5 \mathrm{~h}$ to remove the residual solvent.

\subsection{Amount and isomer analysis of CLA}

$\mathrm{Ag}^{+}-\mathrm{HPLC}$ separation of the CLA methyl esters was carried out using a high performance liquid chromatography system (Shimadzu LC-20A/Prominence) equipped with a $20 \mu \mathrm{l}$ injection loop (Shimadzu CBM-20Alite System Controller), UV-VIS detector (Shimadzu SPD-20A) operated at $233 \mathrm{~nm}$, a column oven (Shimadzu CTO-10AS VP) at $25^{\circ} \mathrm{C}$, and an operating system (LC-Solution). Two ChromSpher 5 Lipids analytical silver-impregnated columns (4.6 mm i.d. $\times 250 \mathrm{~mm}$ stainless steel; $5 \mu \mathrm{m}$ particle size; Chrompack, Bridgewater, NJ) were used in series. The mobile phase was $0.1 \%$ acetonitrile in hexane and operated 


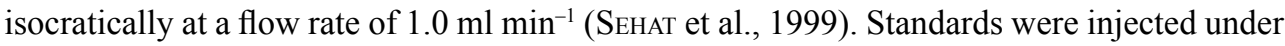
the same conditions for the determination of isomers.

\subsection{Determination of optimum conditions and statistical analysis}

D-optimal cubic design was employed in optimization studies of CLA production, which generated 25 experimental runs that were carried out subsequently. Design Expert 8.0.7.1 package program (Stat-Ease Inc., Minneapolis, MN, USA) was used for regression analysis and analysis of variance. On the other hand, the data was analyzed by One-Way ANOVA, and multiple comparisons of the means were undertaken using Duncan's test using SPSS (SPSS Inc., Chicago, IL) for results of CLA purification.

\section{Results and discussion}

\subsection{Fatty acid composition of purified $L A$}

Fatty acid composition of purified LA and safflower oil were determined. The results of analysis showed that while safflower oil had $57.3 \pm 1.3 \%$ LA as dominant fatty acid, purified LA had high LA content $(98.5 \pm 0.01 \%)$ and low other fatty acid content $(1.5 \pm 0.00 \%)$.

\subsection{Optimization of CLA production}

The results of CLA production at different temperatures $\left(80-240{ }^{\circ} \mathrm{C}\right)$ and different times $(1-10 \mathrm{~h})$ are given in Figure 1. For all CLA isomers, the amount of production increased with the increase of temperature and time. However, after $8 \mathrm{~h}$, the amount of undesirable isomers increased more than the others (Fig. 1).
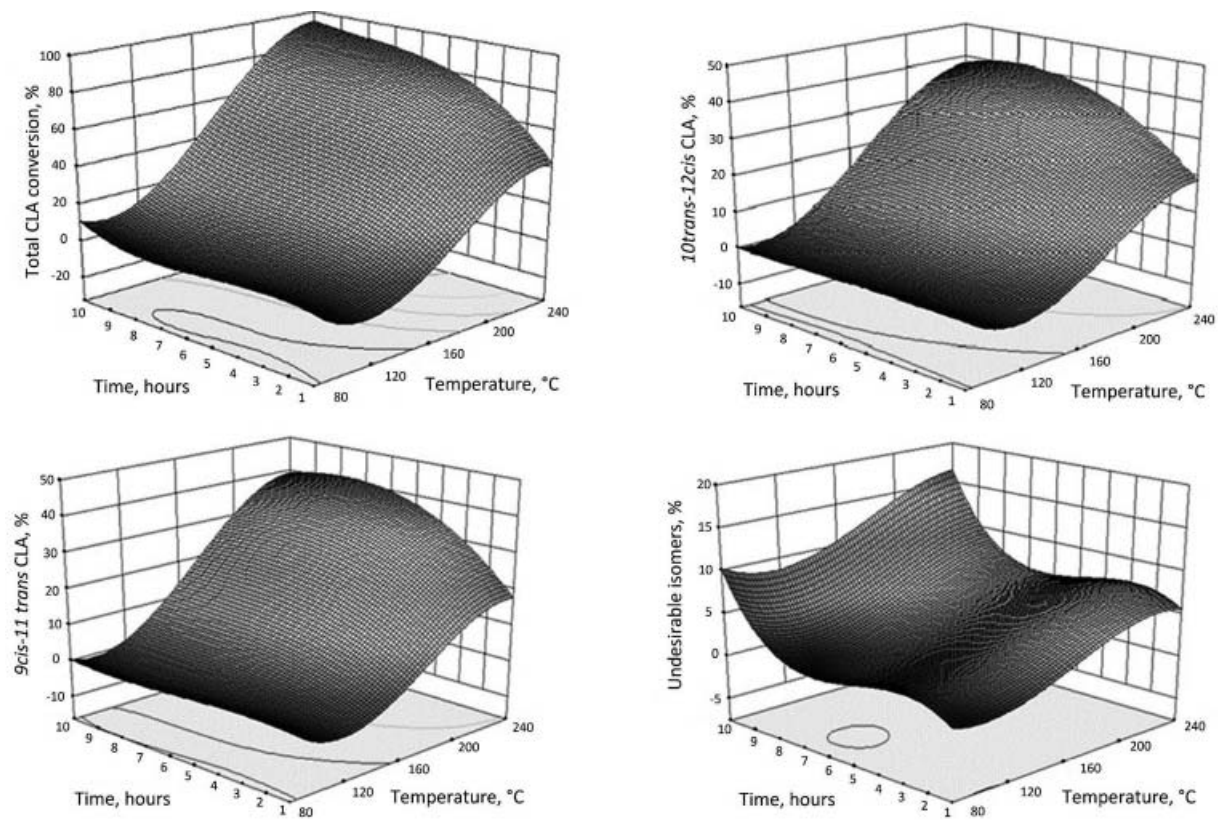

Fig. 1. Graphs showing the effect of reaction conditions on the conversion of LA into CLA isomers 
Total CLAs were produced by alkali isomerisation up to ca. $90 \%$ of total fatty acids from purified LA at $240{ }^{\circ} \mathrm{C}$ for $10 \mathrm{~h}$. However, under these conditions, $19.2 \%$ undesirable isomers, $37.0 \%$ trans-10, cis-12 CLA, and 37.5\% cis-9, trans-11 CLA were obtained (Fig. 1). Optimum conditions were determined using the Design Expert 8.0.7.1 package program, and then they were experimentally verified (Table 1). Alkali isomerisation allowed $87.68 \%$ conversion under optimum conditions $\left(240{ }^{\circ} \mathrm{C}\right.$ for $\left.8 \mathrm{~h}\right) ; 40.96 \%$ for trans- 10 , cis-12 CLA, $40.37 \%$ for cis-9, trans-11 CLA, and $6.35 \%$ for undesirable isomers. The estimated and experimental data were verified by relative standard error (RSE):

$$
\mathrm{RSE}, \%=\frac{\text { Experimental value-Estimated value }}{\text { Estimated value }} \times 100
$$

The results showed insignificant difference between the estimated and experimental values for CLA isomers. Therefore, D-optimal cubic design is acceptable to be used in production of beneficial CLA isomers by alkali isomerisation.

CLAs are commercially produced mostly by alkali isomerisation of LA with high yields of 90-93\% (MA et al., 1999; KIM et al., 2003). A temperature of $150{ }^{\circ} \mathrm{C}$ and a period of 140 min were previously found to be the optimal conditions for the isomerisation process for the production of trans-10, cis-12 and cis-9, trans-11 isomers (YANG \& LiU, 2004). In contrast, in this study, the optimum conditions for beneficial isomers (trans-10, cis-12 and cis-9, trans-11) were determined as $240{ }^{\circ} \mathrm{C}$ for $8 \mathrm{~h}$.

$\mathrm{MA}$ and co-workers (1999) reported that a lower temperature between $160-180{ }^{\circ} \mathrm{C}$ reduced the amount of undesirable CLA isomers produced from safflower oil. However, in this presented study, it was determined that although the reaction temperature was effective, the reaction time should not be longer than $8 \mathrm{~h}$ for undesirable CLA isomer production below $10 \%$. On the other hand, trans-9, trans-11, another beneficial isomer for health (YAsur et al., 2007), was only detected in trace amount.

In a research conducted in 2017 (LIU et al., 2017), it was determined that chemical isomerisation with $\mathrm{Ru}$ supported the conversion of LA to CLA by $51.3 \%$ in non-hydrolyzed cottonseed oil. On the other hand, GoLI and co-workers (2008) reported that two important isomers of CLA; i.e., trans-10, cis-12 and cis-9, trans-11, were produced up to ca. $73 \%$ of total fatty acids during the alkali isomerisation of safflower oil. The results of the current study determined that these two important CLA isomers were produced up to $81.4 \%$ of the total fatty acids.

\subsection{Purification of CLAs by low temperature crystallization}

For this process, alkali isomerisation was carried out again under the optimum conditions of $240{ }^{\circ} \mathrm{C}$ for $8 \mathrm{~h}$ that resulted in a total conversion of $87.8 \%$. The final product was composed of $41.0 \%$ trans -10 , cis- 12 CLA, $40.4 \%$ cis- 9 , trans- 11 CLA, and $6.4 \%$ undesirable isomers (Table 2). Then, the CLA solutions containing different solvents (acetone, methanol, and petroleum ether) were crystallized at various temperatures $\left(0\right.$ to $\left.-85{ }^{\circ} \mathrm{C}\right)$. Although crystallization of CLA did not occur at $0,-10,-25$, and $-40^{\circ} \mathrm{C}$, crystals of fatty acid were obtained at $-55,-70$, and $-85^{\circ} \mathrm{C}$. The highest decrease of LA and undesirable CLA isomers was observed after $48 \mathrm{~h}$, at $-55^{\circ} \mathrm{C}$. These conditions caused a decrease over $40-50 \%$ of LA and undesirable CLA isomers with respect to their initial concentration in the CLA solution. On the other hand, the percentage of CLA was reduced and the yield increased with the decrease of temperature. The results showed that the highest beneficial CLA concentrates $(91.0 \%)$ were obtained at $-55{ }^{\circ} \mathrm{C}$ with a yield of $38.1 \%$ when acetone was used as the solvent 
$(5 \mathrm{~g} / 100 \mathrm{ml})$. However, the highest yield $(74.1 \%)$ of crystallizing fatty acids was observed at $-85^{\circ} \mathrm{C}$. Lastly, the highest trans- 10 , cis- $12 \mathrm{CLA}$ content $(63.6 \%)$ was obtained at $-55^{\circ} \mathrm{C}$ (in acetone).

Using methanol as the solvent, it was found that $36.9 \%$ of the CLA solution solidified at $-55^{\circ} \mathrm{C}$, and $89.5 \%$ healthy CLA isomers and $3.2 \%$ other CLA isomers were obtained. Solid fatty acids at $-85{ }^{\circ} \mathrm{C}$ were composed of $42.3 \%$ trans -10 , cis- 12 and $42.2 \%$ cis- 9 , trans- 11 CLA concentrates with a yield of $70.3 \%$. The highest yields were achieved at $-55,-70$, and $-85^{\circ} \mathrm{C}$ with the use of petroleum ether as the solvent, and these values were $73.5,82.2$ and $89.6 \%$, respectively. However, the CLA content of the obtained fatty acids had a lower purity value than the others (Table 2). HPLC chromatograms of CLA standards (A), unpurified CLA solution (B), and purified CLA (C) at $-85^{\circ} \mathrm{C}$ with the use of petroleum ether as the solvent $(88.1 \%)$ are given in Figure 2.
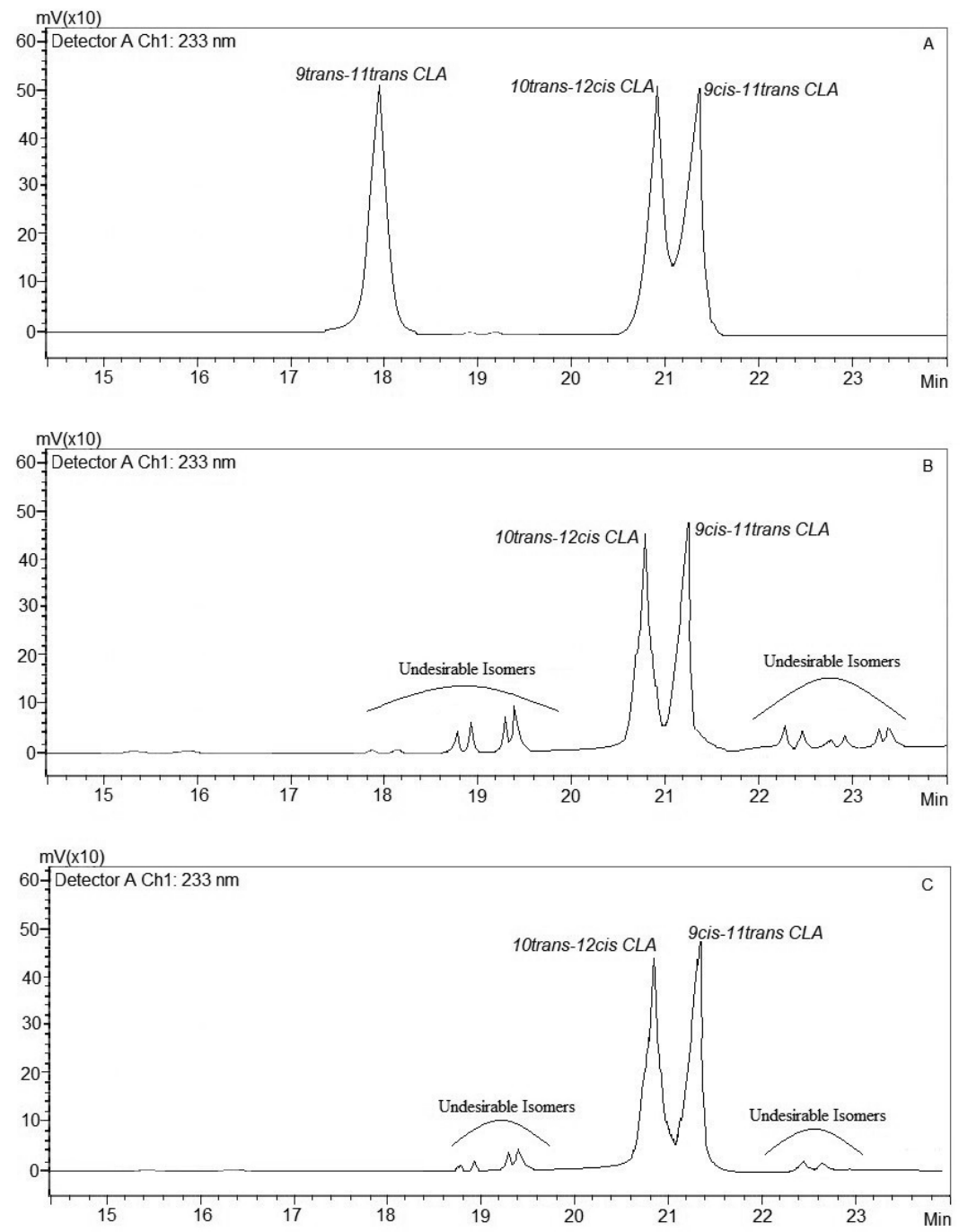

Fig. 2. Chromatograms of CLA standards (A), unpurified CLA solution (B), and purified CLA (C) at $-85^{\circ} \mathrm{C}$ with the use of petroleum ether 


$$
\text { 雷 }
$$


It has been reported that chemically produced CLA can be purified to $90-95 \%$ using the urea crystallization method (KIM et al., 2003). However, GoLI and co-workers (2008) obtained a product containing $73 \%$ CLA from safflower oil by alkali isomerisation, and then elevated the CLA level to $85.6 \%$ by urea crystallization. The urea crystallization process is multi-stage with low yield; however, the results of the current study demonstrated that it is possible to obtain CLA with a high purity (over 90\%) and high yield (over 70\%) in just one step using the low temperature crystallization method.

\section{Conclusions}

CLA is chemically produced from linoleic acid by alkali isomerisation. This commercial synthesis has focused on maximizing the total CLA content without considering the CLA isomers that are formed; however, not all CLA isomers are useful for maintaining health. In this work, it was determined that the amount of all CLA isomer production increased with the increase of temperature and reaction time. However, the amount of undesirable isomers increased more than the other isomers after $8 \mathrm{~h}$. Alkali isomerisation also resulted in an equal amount of trans-10, cis-12 and cis-9, trans-11 CLA isomers, but no another beneficial isomer (trans-9, trans-11 CLA).

On the other hand, CLA purification by low temperature crystallization revealed a significant decrease in the amount of LA and undesirable CLA isomers when crystallization was conducted at $-55^{\circ} \mathrm{C}$. In addition, as the temperature decreased, more CLA crystals were obtained but the purity of final products was reduced.

The authors thank the Turkish Scientific Council TUBITAK (TOVAG 213O129) for providing funding for the project.

\section{References}

CHRISTIE, W.W. (1989): The preparation of derivatives of fatty acids. -in: Gas chromatography and lipids, a practical guide, Oily Press, Ayr, Scotland, Ch. 4., pp. 65-68.

Cunha, D.C., Crexi, V.T., Pinto, L.A. \& De, A. (2009): "Winterizaçao" de oleo de pescado via solvent (Winterization of fish oil with solvent). Cienc. Tecnol. Aliment., 29, 207-213.

Erinç, H., Erinç, Ö., GerçEK, H. \& Y ILDIRIM, Z. (2017): Mikrobiyal ve kimyasal yöntemlerle konjüge linoleik asit üretimi (Conjugated linoleic acid production with microbial and chemical methods), TUBITAK project report, Ankara, Turkey.

Fernie, C.E. (2003): Conjugated linoleic acid. -in: Gunstone, F.D. (Ed.) Lipids for functional food and nutraceuticals. Vol. 3., The Oily Press, Bridgewater, U.K., pp. 291-318.

Gnadig, S. Rickert, R. Sebedio, J.L. \& Steinhart, H. (2001): Conjugated linoleic acid (CLA); Physiological effects and production. Eur. J. Lipid Sci. Technol., 103, 56-61.

Goli, S.A.H., Kadivar, M., Keramat, J. \& Fazilati, M. (2008): Conjugated linoleic acid (CLA) Production and lipase-catalyzed interesterification of purified CLA with canola oil. Eur. J. Lipid Sci. Tech., 110, 400-404.

Gunstone, F.D., Harwood, J.L. \& Dijkstra, A.J. (2007): The lipid handbook with CD-ROM, $3^{\text {rd }}$ ed., CRC Press, Boca Raton, London, New York. pp. 471-535

HA, Y.L., Grimm, N.K. \& PARIZA, M.W. (1987): Anticarcinogens from fried ground beef: Heat-altered derivatives of linoleic acid, Carcinogenesis, 8, 1881-1887.

Kim, Y.J., Lee, K.W., Lee, S., Kim, H. \& LeE., H.J. (2003): The production of high-purity conjugated linoleic acid (CLA) using two-step urea-inclusion crystallization and hydrophilic arginine-CLA complex, J. Food Sci., 68, 1948-1951. 
Liv, S., Wang, Z., Xu, X., Ding, Y. \& Guo, Z. (2017): Production of conjugated linoleic acid-rich cottonseed oil by supported Ru catalyzed isomerization. Ind. Crop. Prod., 97, 10-20.

MA, D.W.L., Wierzbicki, A.A., Field C.J. \& Clandinin, M.T. (1999): Preparation of conjugated linoleic acid from safflower oil. J. Am. Oil Chem. Soc., 76, 729-730.

Nagao, K., Wang, Y.M., Inoue, N., Han, S.Y., Buang, Y., Noda, T., Kouda, N., Okamatsu, H. \& Yanagita, T. (2003): The 10 trans, 12 cis isomer of conjugated linoleic acid promotes energy metabolism in OLEFT rats. Nutrition, 19, 652-656.

Rahman, S.M., Wang, Y., Han, S., Cha, J., Fukuda, N., Yotsumoto, H. \& Yanagita, T. (2001): Effects of short-term administration of conjugated linoleic acid on lipid metabolism in white and brown adipose tissues of starved/ refed Otsuka Long-Evans Tokushima fatty rats. Food Res. Int., 34, 515-520.

Sehat, N., Rickert, R., Mossoba, M.M., Kramer, J.K.G., Yurawecz, M.P., Roach, J.A.G., Adlof, R.O., Morehouse, K.M., Fritsche, J., Eulitz, K.D., Steinhart , H. \& Ku, Y. (1999): Improved separation of conjugated fatty acid methyl esters by silver ion-high-performance liquid chromatography. Lipids, 34, 407-412.

Van Nieuwenhove, C.P., Teran, V. \& Gonzalez, S.N. (2012): Conjugated linoleic and linolenic acid production by bacteria: Development of functional foods. -in: Rigobelo, E.C. (Ed.) Probiotics, InTechOpen Publisher. 642 pages.

Viladomiua, M., Hontecillasa, R. \& Bassaganya-Riera, J. (2016): Modulation of inflammation and immunity by dietary conjugated linoleic acid. Eur. J. Pharmacol., 785, 87-95.

Wanasundara, U.N., Wanasundara, P.K.J.P.D. \& Shahidi, F. (2005): Novel separation techniques for isolation and purification of fatty acids and oil by-products. -in: SHAHIDI, F. (Ed.) Bailey's industrial oil and fat products, John Wiley \& Sons, New York. pp. 585-621.

YANG, T.S. \& LiU, T.T. (2004): Optimization of production of conjugated linoleic acid from soybean oil. J. Agr. Food Chem., 52, 5079-5084.

Yasui, Y., Suzuki, R., Kohno, H., Miyamoto, S., Beppu, F., Hosokawa, M., Miyashita, K. \& Tanaka, T. (2007): 9trans,11trans conjugated linoleic acid inhibits the development of azoxymethane-induced colonic aberrant crypt foci in rats. Nutr. Cancer, 59, 82-91. 